\title{
SPECTRAL MIXTURE ANALYSIS (SMA) OF LANDSAT IMAGERY FOR LAND COVER STUDY OF HIGHLY DEGRADED PEATLAND IN INDONESIA
}

\author{
A. D. Saktia,b*, S. Tsuyuki ${ }^{b}$ \\ a.Center for Remote Sensing, Bandung Institute of Technology, Bandung, Indonesia -anjardimara@ yahoo.com \\ b. Global Forest Environmental Studies, Graduate School of Agricultural and Life Sciences, The University of Tokyo, Japan \\ - tsuyuki@fr.a.u-tokyo.ac.jp
}

\section{Commission VI, WG VI/4}

KEY WORDS: Tropical Peatland Degradation, Spectral Mixture Analysis, Endmember Analysis, Burned Peat Fraction, Pelalawan District.

\begin{abstract}
:
Indonesian peatland, one of the world's largest tropical peatlands, is facing immense anthropogenic pressures such as illegal logging, degradation and also peat fires, especially in fertile peatlands. However, there still is a lack of appropriate tools to assess peatland land cover change. By taking Pelalawan district located in Sumatra Island, this study determines number of land cover endmembers that can be detected and mapped using new generation of Landsat 8 OLI in order to develop highquality burned peat fraction images. Two different image transformations, i.e. Principle Component Analysis (PCA), Minimum Noise Fraction (MNF) and two different scatterplot analyses, i.e. global and local, were tested and their accuracy results were compared. Analysis of image dimensionality was reduced by using PCA. Pixel Purity Index (PPI), formed by using MNF, was used to identify pure pixel. Four endmembers consisting of two types of soil (peat soil and dry soil) and two types of vegetation (peat vegetation and dry vegetation) were identified according to the scatterplot and their associated interpretations were obtained from the Pelalawan Fraction model. The results showed that local scatterplot analysis without PPI masking can detect high accuracy burned peat endmember and reduces RMSE value of fraction image to improve classification accuracy.
\end{abstract}

\section{INTRODUCTION}

Indonesia is one of the countries having the largest tropical peatlands area in the world. The country's peatland is facing immense anthropogenic pressures such as illegal logging, degradation and peat fires, especially in fertile peatlands (Margono, 2014). However, there still is a knowledge gap in terms of understanding extent of pressure faced by peatlands as well as appropriate tools to assess land cover change. Remote sensing technology is one of the useful tools for monitoring condition of forest ecosystem such as deforestation and forest degradation (Souza, 2005).

Land-cover classification using medium spatial resolution data such as Landsat is often difficult because of limitations in spatial resolution of the data and the heterogeneity of features on the ground especially for successional stages in a degraded tropical forest region (Souza, 2000; Stone, 1998; Eraldo, 2010). This problem often produces poor classification accuracy when conventional algorithms such as the maximum likelihood classifier are used. Several methods have been developed to solve the mixed pixels problem, one of them being the Spectral Mixture Analysis (SMA).

The main objective of this paper is to determine number of land cover endmembers that can be detected and mapped using new generation of Landsat $8 \mathrm{OLI}$ in order to develop high-quality burned peat fraction images.

* Corresponding author
In order to achieve the objective, two different image transformations, pure pixel identification method, and two different scatterplot strategies were tested and their accuracy results were compared.

\section{STUDY AREA AND PRE-ANALYSIS OF IMAGERY DATA}

The study was conducted in the Pelalawan district, one of the highly degraded peatland area in Indonesia (Tanuwijaya et al., 2014; Supriatna, 2014). It is located between $100^{\circ} 42^{\prime}$ and $103^{\circ} 28^{\prime} \mathrm{E}$ longitudes and $1^{\circ} 25^{\prime}$ and $0^{\circ} 20^{\prime} \mathrm{S}$ latitudes, and the district is $77 \mathrm{~km}$ from Pekanbaru (the capital of Riau province) (Figure 1a). Land cover condition in Pelalawan region consisted of land with a high peat content (wet) and dry land (Meilani et al., 2011). Landsat 8 OLI data of 16 June, 2013 was geometrically rectified using control points taken from topographic maps at 1: 250000 scale (Universal Transverse Mercator (UTM), south 48 zone). A nearestneighbor resampling technique was used and a root mean square error with less than 0.4 pixel was obtained.

A maximum likelihood classifier was used to classify images into ten land cover classes: low impervious surface area, burned peat, clear cut trees, dry soil area, primary forest, acacia forest plantation, oil palm plantation, shrub area, young plantation, and peat swamp forest. 183 plots were identified during the fieldwork in the dry season of September 2014, representing 10 different land covers. Using the field data, it was able to obtain $85 \%$ of overall accuracy on preliminary image classification (Figure 1b). 
Majority of the accuracy shortcoming can largely be attributed to the heterogeneous pixel of the area, such as burned peat, shrub, young plantation and low impervious surface area. This has most likely contributed to errors in the image interpretation.

\section{RESEARCH METHODS}

\subsection{High Accuracy Endmember}

Endmember selection is a salient aspect in SMA analysis to develop high-quality fraction image (Lu, 2002). Following the procedure proposed by (Smith et al., 1985), we selected the extreme pixel clusters which bound almost all other pixels as endmembers using scatterplot. In this study we used two strategies of scatterplot, global scatterplot and local scatterplot.

The global scatterplot was used to analyse the whole area of Pelalawan region. Hence, the entire pixels distribution in all classes were directly analyzed and compared to an extreme levels on the scatterplot.

The other one was local scatterplot which is the next stage to analyze using the global scatterplot. It was used for detail analysis of extreme pixel candidates that were detected during global scatterplot analysis. Local scatterplot visualization tool, available in ENVI 5.2 Classic, was used for detail visualization. Extreme pixels in both scatterplot were recorded and marked as endmember pixels.

To obtain the extreme values, transformation methods that change the original data to a new dataset by reducing redundancy, were used. However, there is a lack of guidelines to identify which endmember selection method is most suitable for a specific study area, hence different authors use different methods (Lu, 2004).

This study employed Principal Component Analysis (PCA) (Wu, 2004) and Minimum Noise Fraction (MNF) (Wu, 2003) transformation methods.
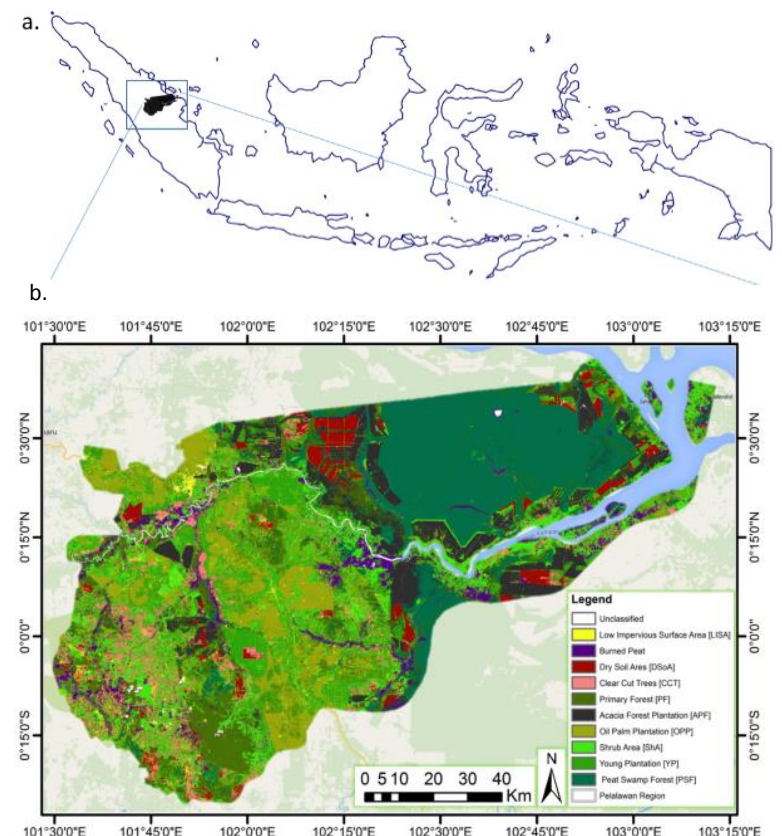

Figure 1. (a). The study area of Pelalawan District, Riau Province, Indonesia, (b). Supervised classification result in Pelalawan region.

Transformed images were then extracted from the reference image. The two transformation methods were also used to analyze Pixel Purity Index (PPI) (Boardman, Kruse, \& Green, 1995; Lu, 2002).

The PPI was used to develop pure spectral area. The pure spectral area then used to mask the whole spectral scatterplot. This masking results in pure spectral scatterplot which does not contain image with mixed pixel. Hence, the final selected endmembers were without mixed pixels.

To identify the highly accurate endmembers, best pixels located at the extremes of the data were selected based on the comparison between four different strategy models: PCA/MNF spectral + global scatterplot, PCA/MNF spectral + local scatterplot, $\mathrm{PCA} / \mathrm{MNF}$ pure spectral + global scatterplot and PCA/MNF pure spectral + local scatterplot (Figure 2).

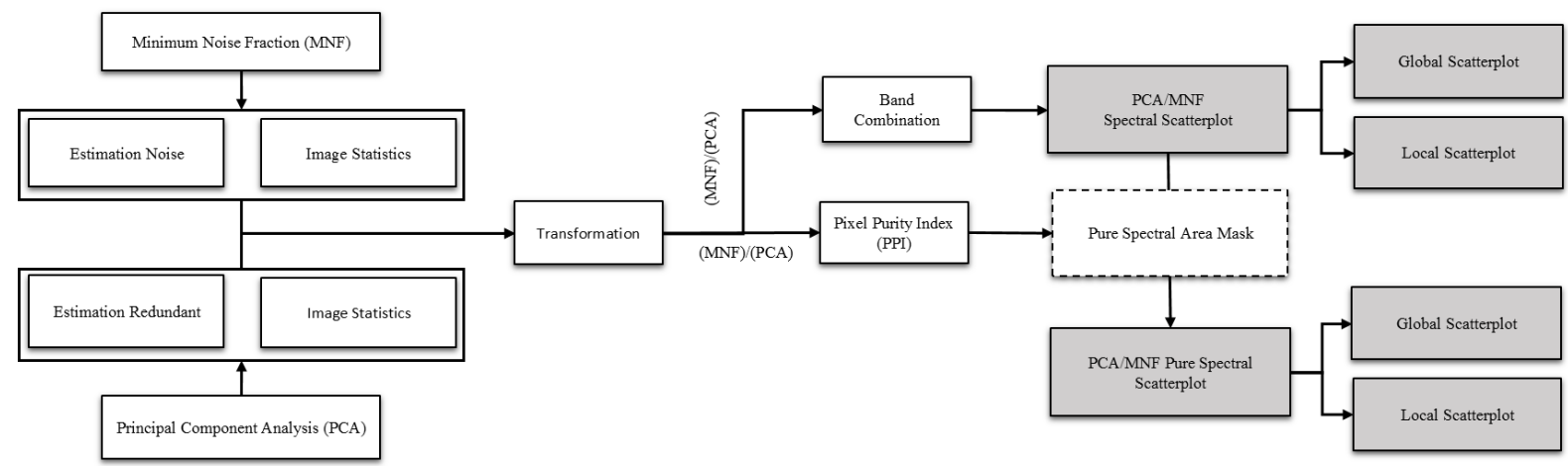

Figure 2. The process of candidate endmember selection of each endmember combination based on four strategy models: PCA/MNF Spectral + Global scatterplot, PCA/MNF spectral + Local Scatterplot, PCA/MNF pure spectral + Global scatterplot, and PCA/MNF pure spectral + Local Scatterplot. 


\subsection{Pelalawan Fraction Mode}

The Pelalawan fraction model was proposed to integrate dry land and peat land cover in Pelalawan area (Figure 3). It was developed based on Vegetation, Impervious Surface and Soil (V-I-S) fraction model (Ridd, 1995), and Vegetation, Nonphotosysnthetic vegetation and shade (V-NP-S) fraction model (Souza, 2003). Based on Pelalawan fraction model, four kinds of endmember candidate consisted of two types of soil (Peat Soil and Dry Soil) and two types of vegetation (Peat Vegetation and Dry Vegetation) were used independently.

Verification of the information model was done by n-dimensional visualization tool available in ENVI based on the Landsat PCA spectral (Figure 4). The clear delineation of 3-D visualizer of Pelalawan fraction image data corresponding to the first three PCA components suggests that the reflectance spectra of the OLI image might best be represented by a four-endmember linear mixing model.

The dry vegetation endmember was identified from the areas of shrub, peat vegetation endmember that was selected from the areas of acacia forest, dry soil endmember was successfully selected from dry soil, and peat soil endmember was selected from the areas of burned peat.

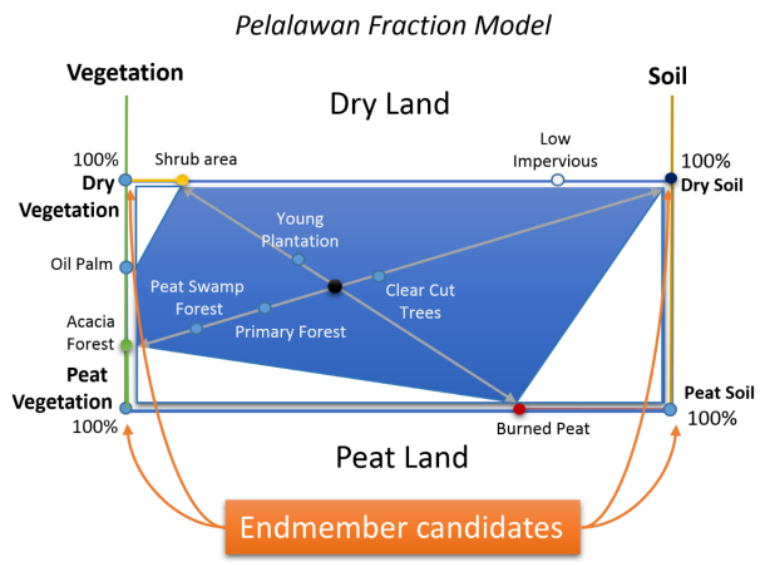

Figure 3. Pelalawan Fraction Model developed from several model fractions that has been studied previously as a parameter of land cover conditions in Pelalawan region consisted of land with a high peat content (wet) and dry land.
Following the procedure proposed by (Rashed et al., 2001), endmembers is representative homogeneous pixels from satellite images through visualizing spectral scatterplots of image band combinations. In this study, however, the fourth endmember, i.e., burned peat endmember was selected despite containing heterogeneous pixels. This is because the goals of this study is to identify burned peat distribution. Therefore the burned peat endmember was assumed to be pure to be used as endmember.

\subsection{Spectral Mixture Analysis}

With known number of endmembers and giving the spectral reflectance of each endmember, the observed pixel value in any spectral band is modelled by linear combination of the spectral response of endmember component within the pixel. The process of solving for endmember fractions is called spectral mixture analysis (Adams et al., 1993; Shimabukuro \& Smith,1991; Wikantika et al., 2002).

Spectral mixture analysis is an application of linear algebra with the following rules:

$$
R c=\sum_{i=1}^{N}(F i . R i, c)+E c
$$

where $\mathrm{Rc}$ is the apparent surface reflectance in the Landsat 8 OLI band c, Fi is the fraction of endmember i, Ri,c is the reflectance of endmember $\mathrm{i}$ in the Landsat 8 OLI band c. $\mathrm{N}$ is the number of spectral endmembers and $\mathrm{Ec}$ is the error in the Landsat 8 OLI band $\mathrm{c}$ to fit $\mathrm{N}$ endmembers.

RMSE ( $\varepsilon$ ) was calculated for each pixel based on the difference between the modelled and measured reflectance of each pixel (Roberts et al., 1993) While the average root mean squared (RMS) error was calculated as follows:

$$
\varepsilon=\left[\frac{1}{m} \sum_{j=1}^{m}\left(R_{\text {measured }}-R_{\text {mod eled }}\right)^{2}\right]^{\frac{1}{2}}
$$

Where $m$ is the number of the Landsat 8 OLI bands used in the spectral mixture analysis.

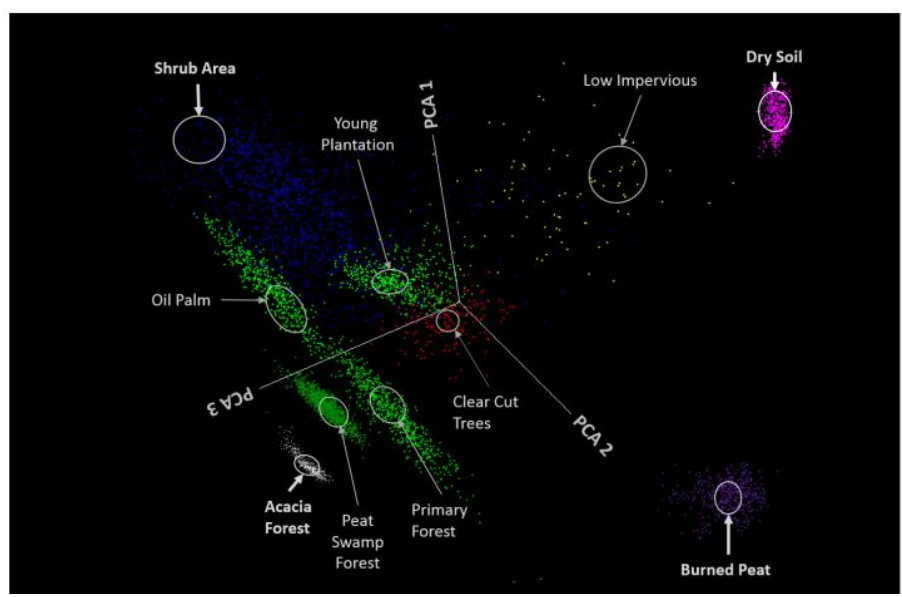

Figure 4. Three dimensional visualization model of ten land cover classes based on Pelalawan fraction model. 


\section{RESULTS}

\subsection{Endmember Spectral Model Analysis}

By conducting PCA and MNF transformations on global scatterplot analysis, we obtained PCA and MNF components from the OLI reflectance images used to guide image endmember selection. The first two PCA components clearly illustrated spatially coherent contrasts differentiating peat soil, peat vegetation, dry soil and dry vegetation as main component endmembers in Pelalawan fraction model. In the case of MNF, however, transformation result failed to detect the peat soil. Rather, the first two or three MNF components were capable only to detect coherent contrasts differentiating two kinds of cloud (Figure 5).

Possible reason for better performance of PCA method was because PCA components could minimize the influence of band to band correlation (Smith et al., 1985). On the other hand, MNF noise variance in one band might be larger than signal variance in another band in terms of unequal scaling in different bands (Small, 2002). However, PPI was more successfully transformed using MNF band composites. MNF band component was successful to calculate repeatedly in scatter diagram plots by iterating projection on the vector unit which was applied to determine the purest pixels.

Based on the above results, endmember fractions in PCA spectral global scatterplot, PCA spectral local scatterplot, PCA pure global scatterplot, and PCA pure spectral local scatterplot combinations were calculated by solving a fully constrained four-endmember linear mixing model using the Landsat 8 OLI reflectance data. Figure 6 shows comparisons between reflectance image, PPI image and PCA image to create PCA pure spectral using local scatterplot.
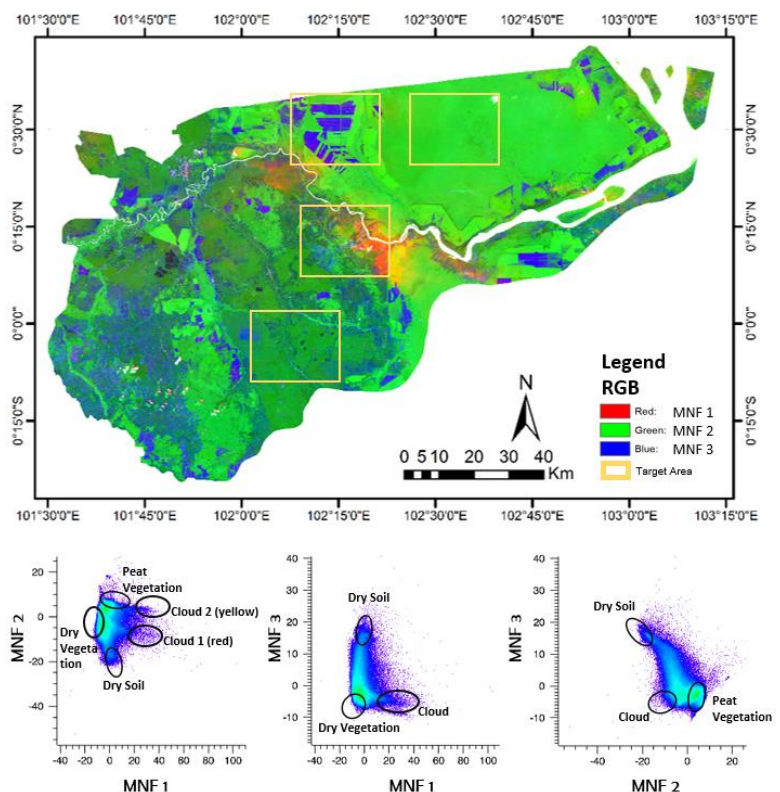

Figure 5. Comparison between PCA transformations and the first-three components result (right) and MNF transformations and the first-three components result (left) on global scatterplot analysis endmember reflectance spectra identified through and the first-three components result (left) on global scatterplot analysis ending
the analysis of the scatterplot.
In order to compare the performance between fraction images transformed by PCA scatterplot and PCA pure scatterplot using global and local scatterplots, the RMSE for every fraction model was calculated.

Table 1 summarizes the RMSE accuracies using different processing models. The pixel value below 0 or more than 1 in all endmember fraction were classified as outlier. Because of this, almost $40 \%$ of the data in PCA pure spectral value were lost. This is why the accuracy value of PCA pure spectral value was relatively small compared with the models that did not use the PPI masking. Therefore, the use of PPI masking is not recommended, especially in monitoring burned peat class.

RMSE of the fraction image transformed by PCA spectral using local scatterplot was 0.232156 , where the value is slightly smaller than the 0.232342 of PCA scatterplot using global scatterplot which suggests both of strategies were generally good fit (less than 0.5). This implies that fraction images with PCA spectral using local scatterplot method without PPI analysis can be the best combination strategy to detect endmember in Pelalawan region.

Table 1. Statistic assessment comparisons of four endmembers fraction image and estimation accuracy for four endmember selection strategies.

\begin{tabular}{ccccccccc}
\hline \multirow{2}{*}{$\begin{array}{c}\text { Statistic } \\
\text { Assessment }\end{array}$} & \multicolumn{2}{c}{$\begin{array}{c}\text { PCA Spectral } \\
\text { Global Scatterplot }\end{array}$} & \multicolumn{2}{c}{$\begin{array}{c}\text { PCA Spectral } \\
\text { Local Scatterplot }\end{array}$} & \multicolumn{2}{c}{$\begin{array}{c}\text { PCA Pure Spectral } \\
\text { Global Scatterplot }\end{array}$} & \multicolumn{2}{c}{$\begin{array}{c}\text { PCA Pure Spectral } \\
\text { Local Scatterplot }\end{array}$} \\
\cline { 2 - 9 } & Min & Max & Min & Max & Min & Max & Min & Max \\
\hline Dry Soil & -5.413 & 3.886 & -5.361 & 3.926 & -19.710 & 2.937 & -12.607 & 2.208 \\
Shrub & -2.837 & 6.480 & -2.667 & 4.961 & -1.491 & 10.757 & -1.487 & 10.656 \\
Burned Peat & -4.186 & 10.989 & -4.166 & 10.729 & -3.741 & 36.863 & -2.948 & 28.724 \\
Acacia & -11.038 & 4.533 & -8.671 & 4.619 & -26.028 & 4.772 & -24.422 & 4.635 \\
RMSE & \multicolumn{2}{c}{0.232342} & 0.232156 & 0.100485 & 0.085121 \\
\hline
\end{tabular}
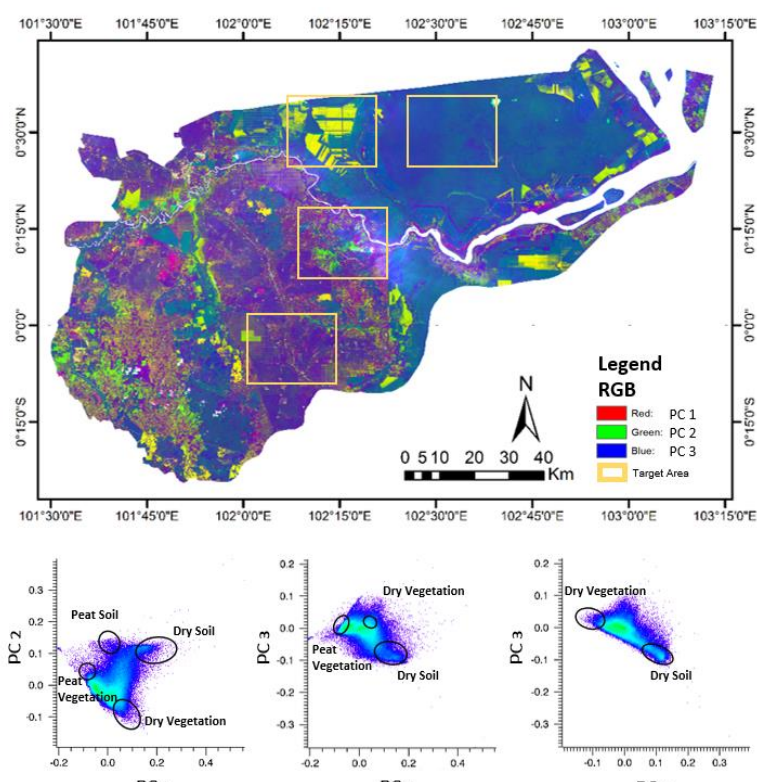


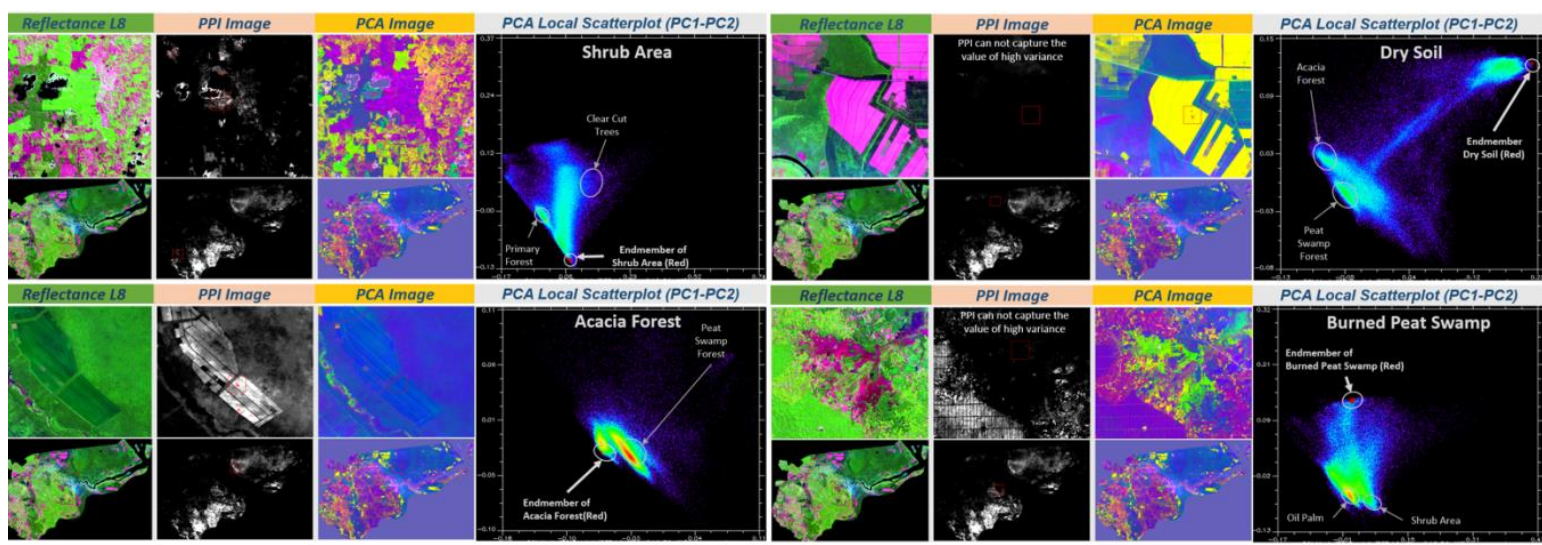

Figure 6. Local scatterplot representation of the first-two PCA components combined with PPI analysis and four endmember reflectance spectra identified through the analysis of the scatterplot.

\subsection{Burned Peat Endmember Fraction Image Analysis}

Theoretically, if all of the pixels are within a quadrangle that is formed by endmembers, a mixture model can be considered as an ideal linear model. In this study, there is an outward curvature along the edge of the peat vegetation and dry vegetation and inward curvature along the edge of dry soil and dry vegetation in the scatter plot of PCA components 1 and 2 (Figure 7). This implies that existence of some nonlinear mixture among these endmembers. Moreover, the selection of peat soil endmember (burned peat class) is difficult because it does not cluster well in the scatterplot. We selected this endmember from highly reflected burned peat in the Pelalawan area because of the study's special interest on degraded peatland especially burned peat surface.

One consequence was fraction values of pixels lying outside could not achieve the range of 0 to 1 , and it did not meet the Adams et al., (1993) criteria. He proposed to inspect the histograms of fraction images and quantify percentage of pixels lying outside the range of 0 to 1 and to evaluate fraction value consistency over time. Only model with at least $98 \%$ of the values within 0 to 1 and those that showed mean fraction value consistent over time were kept.

Overall, the endmember spectra shows that this model represents shrub , acacia forest, dry soil, and burned peat cover types very well because among whole endmember fractions, pixels fraction distribution remained predominantly in the range of 0 to 1 . However, the performance was not satisfactory for modelling some endmember fraction material in the study area.

Figure 8 shows the distribution of burned peat fraction based on PCA pure spectral transformation using local scatterplot. Although the fraction statistic value results showed that the burned peat fraction range distributed from -4.16 to 10.73 , most of the fraction values were distributed in the range of 0-1 (figure 9). Acacia class and some parts of peat swamp forest class had a fraction value less than 0 . Therefore, the faction of burned peat assumed these classes as outlier with no value in the fraction image.

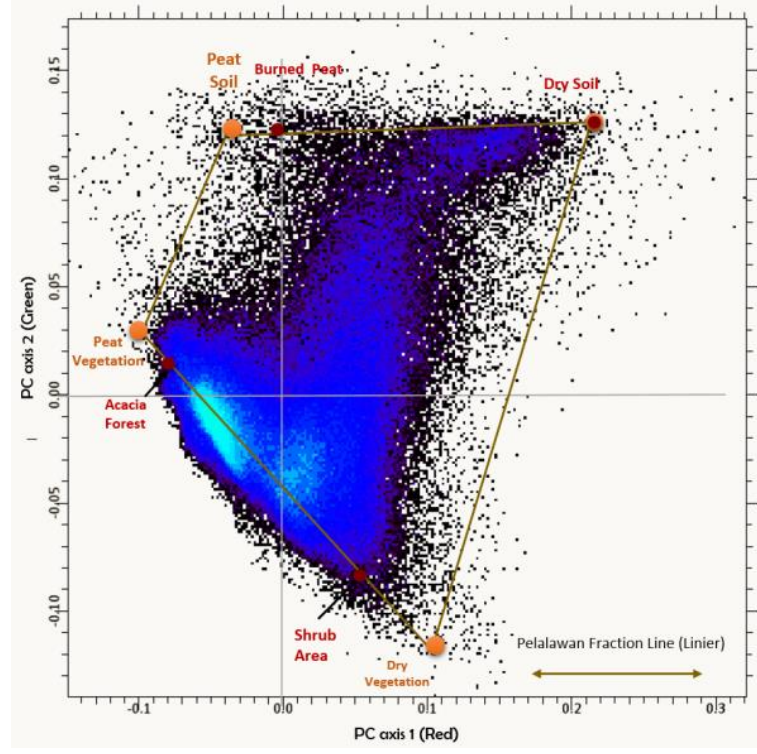

Figure 7. Scatterplot of endmember spectra in based on Pelalawan Fraction Line.

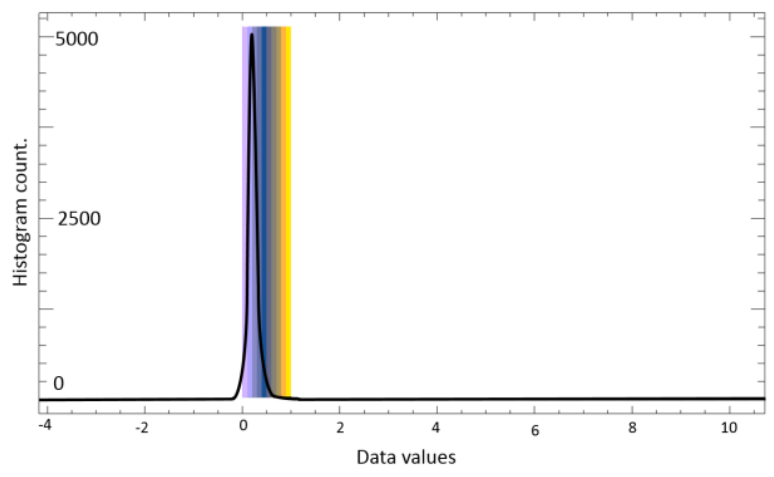

Figure 9. Histogram of burned peat fraction derived from PCA spectral using local scatterplot. 


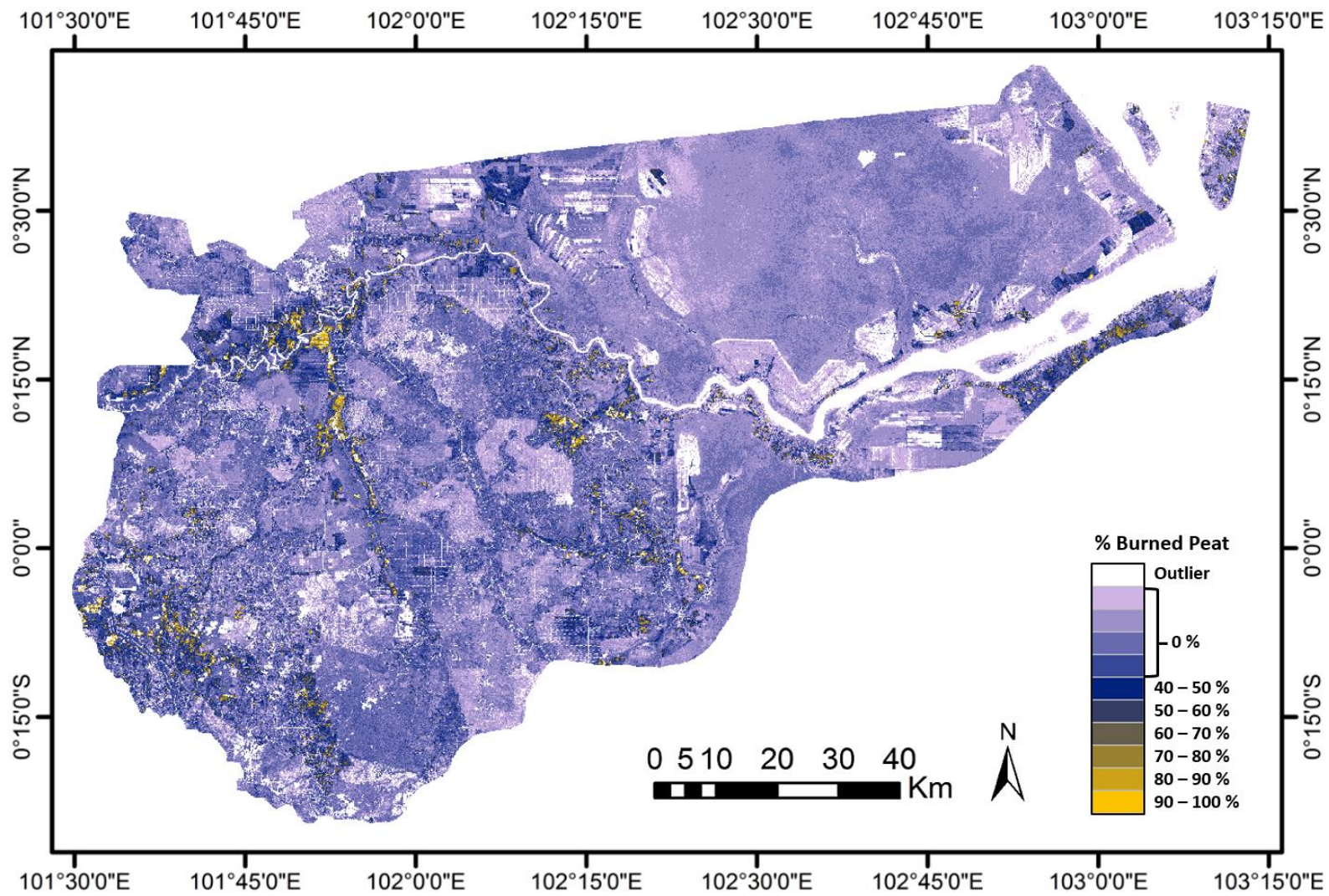

Figure 8. Burned peat fraction imagery derived from PCA spectral using local scatterplot.

The analysis of the ground verification showed that the burned peat area can be accurately detected only above $40 \%$. Therefore, the calculation of the area of burned peat in Pelalawan region was calculated from the value percentage of $40 \%$ and above (Figure 8).

The calculation of total burned Peat area above $40 \%$ using SMA resulted in $428.93 \mathrm{~km}^{2}$ which was less than the area of $898.50 \mathrm{~km}^{2}$ calculated using maximum likelihood. One reason for the disparity is that, unlike the maximum likelihood, the SMA faction image can distinguish burned peat and peat water. Another reason is SMA can better discriminate between different classes in mixed pixel class than the maximum likelihood approach.

\section{CONCLUSION}

This study evaluated two different image transformations: i.e., PCA, MNF and two different scatterplot, i.e. global and local, to detect the best endmember which is vital to obtain high quality burned peat fraction image. Analysis of image dimensionality was reduced by using PCA. Pixel Purity Index (PPI), formed by using MNF, was used to identify pure pixel. The result showed that PCA spectral without PPI masking using local scatterplot analysis can successfully detect high accuracy endmember and reduces RMSE value of fraction image to improve classification accuracy.
Hence, fraction image with the scatterplot method could achieve the best combination strategy. However, the burned peat fraction image performance was not satisfactory for modelling all fractions of the study area such as acacia forest and peat swamp because of the linear assumption used in the analysis. Therefore, future research should target testing nonlinear Spectral Mixture Analysis application, using multi temporal data imagery, improving accuracy assessment technic and comparing it with results from current research.

\section{ACKNOWLEDGMENTS}

The authors are grateful to acknowledge the support from Global Forest Environmental Studies Laboratory, The University of Tokyo and also supported through the Global Leader Program for Social Design and Management (GSDM) by the Ministry of Education, Culture, Sport, Science and Technology Japan. 


\section{REFERENCES}

Adams, J. B., Sabol, D. E., Robert, D., Smith, M. O., \& Gillespie, A. R. (1995). Classification of multispectral images based on fractions of endmembers: Application to land-cover change in the Brazilian Amazon. Remote Sensing of Environment, 52, 137-154.

Adams, J. B., Smith, M. O., \& Gillespie, A. R. (1993). Imaging spectroscopy: Interpretation based on spectral mixture analysis. In VM Pieters, \& P. Englert (Eds.), Remote geochemical Analysis: Elementa 1 and Mineralogical Composition. New York: Cambridge Univ.Press.7, 145-166.

Boardman, J. W., Kruse, F. A., \& Green, R. O. (1995). Mapping target signatures via partial unmixing of AVIRIS data. Summaries of the 5th Airborne Earth Science Workshop, January 23-26. JPL Publication, 95(1), 23-26.

Eraldo, A. T. M., Skole, D. L., Pedlowski, M. A., Chomentowski, W., Fernandes, L. C. (2010). Assessment of tropical forest degradation by selective logging and fire using Landsat imagery. Remote Sensing of Environment 114, pp. $1117-1129$.

Hostert, P., Roder, A., Hill, J. (2003). Coupling Spectral Unmixing and Trend Analysis for Monitoring of Long-term Vegetation Dynamics in Mediterranean Rangelands. Remote Sensing of Environment 87, pp. 183-197.

Lu, D., Batistella, M, Moran, E. (2002). Linear Spectral Mixture Analysis of TM Data for Land-use and Land-cover Classification in Rondonia, Brazilian Amazon. Symposium on Geospatial Theory, Processing and Applications.

Lu, D., Batistella, M., Moran, E., Mause, P. (2004) Application of Spectral Mixture Analysis to Amazonian landuse and land-cover Slassification. International Journal of Remote Sensing. Vol. 25, No. 23. Taylor \& Francis Ltd., Pp.5345-5358.

Mariati, S. (2014). Habitat Loss of Sumatran Elephants (Elephasmaximussumatranus) in TessoNilo Forest, Riau, Indonesia. Australian Journal of Basic and Applied Sciences 8(2), Pp 248-255.

Margono, B. A., Potapov, P. V., Turubanova, S., Stolle, F., Hansen, M. C. (2014) Primary Forest Cover Loss in Indonesia Over 2000-2012. Nature Climate Change Online Journal, vol 4, 10.1038/NCLIMATE227

Meilani, A. (2011) Comparison of Land Cover and Forest Plantation Ability Classification Using Landsat TM and ALOS PALSAR-Case Study in Pelalawan, Riau Province, Indonesia. Unpublished doctoral dissertation, the University of Tokyo, Tokyo, Japan.

Rashed, T., Weeks, J. R., Gadalla, M. S. (2001). Revealing the anatomy of cities through spectral mixture analysis of multispectral satellite imagery: a case study of the greater Cairo region, Egypt. Geocarto International, 16(4), pp.5 - 15.

Ridd, MK. (1995). Exploring a VIS (Vegetation-Impervious Surface-Soil) a model for urban ecosystem analysis through remote sensing: Comparative anatomy for cities. International Journal of Remote Sensing, 16: 2165-2185.
Roberts, DA, Batista, GT, Pereira, JL G., Walker, EK, \& Nelson, B. W. (1998). Change identification using multitemporal spectral mixture analysis: Applications in the eastern Amazon. In RS Luneetta, and CD Elvidge (Eds.), Remote Sensing Change Detection: Environmental Monitoring Methods and Applications. Chelsea, MI: Ann Arbor Press, 9, 137-159.

Small, C. (2002). Multitemporal analysis of urban reflectance. Remote Sensing of Environment, 81, 427-442.

Shimabukuro, YE, Smith, JA. (1991). the least squares mixing models to generate fraction images derived from remote sensing multispectral data. IEEE Transactions on Geoscience and Remote Sensing, 29, 16-20.

Smith, M. O., Johnson, P. E., \& Adams, J. B. (1985). Quantitative determination of mineral types and abundances from reflectance spectra using principal component analysis. Journal of Geophysical Research, 90, 792- 804.

Souza Jr. C.M., Firestone, L., Silva, LM, Roberts, D.A. (2003). Mapping of forest degradation in the Eastern Amazon from SPOT 4 through spectral mixture models. Remote Sensing of Environment 87.494-506.

Souza Jr. C. M., Barreto, P. (2000). An alternative approach for detecting and monitoring selectively logged forests in the Amazon. International Journal of Remote Sensing, 21 (1), 173-179.

Souza Jr. C. M., Roberts. D. A., Cochrane. M. A. (2005). Combining Spectral and Spatial Information to Map Canopy Damage from Selective Logging and Forest Fires. Remote Sensing of Environment 98, pp. 329-343.

Stone, TA, Lefebvre, PA. (1998). Using multi-temporal satellite data is to Evaluate selective logging in Para, Brazil. International Journal of Remote Sensing, 13, 2517- 2526.

Supriatna, J. (2014). Degradation of Primate Habitat at TessoNilo Forest with Special Emphasis on Riau PaleThighedSurili (Presbytissiamensiscana). Journal of Environmental Protection, 5, 1145-1152.

Tanuwijaya, BA, et al. (2014). Primary forest cover loss in Indonesia over 2000-2012. Nature Climate Change 4, 730 735 .

Wikantika, K., Uchida, S., Yamamoto, Y. (2002). Mapping Vegetable Area with Spectral Mixture Analysis of the Landsat-ETM. IEEE 0-7803-7536-X.

Wu, C. (2003). Estimating impervious surface distribution by spectral mixture analysis. Remote Sensing of Environment 84. pp, 493-505.

Wu, C. (2004). Normalized spectral mixture analysis for monitoring urban composition using ETM + imagery. Remote Sensing of Environment 93, 480- 492. 